\title{
GÉNERO Y DISCAPACIDAD COMO MODULADORES DE LA IDENTIDAD
}

Recibido: 26/03/2009

GRACE SHUM

Universidad de Huelva

ÁNGELES CONDE

Universidad de Vigo

Aceptado: 28/05/2009

\section{Introducción: Género, discapacidad e identidad}

La conformación del mundo en hombres y mujeres se encuentra con ciertos obstáculos derivados de planteamientos de dominio masculino y de corte patriarcal, cuya mentalidad androcéntrica apoya la consideración de lo masculino como superior. Este hecho se manifiesta social e individualmente de tal modo que los valores de género masculinos sustentan todas las interpretaciones filosóficas, científicas y religiosas. Así, los hombres son considerados superiores a las mujeres. Victoria Sau ${ }^{1}$ señala que los seres humanos organizan y clasifican los conocimientos del mundo de forma dual; cada dimensión tiene su opuesta con la que constituye una organización bipolar. Los dos polos de una misma dimensión no valen lo mismo, sino que uno aparece como positivo y el otro como negativo. Los positivos tienden a unirse con otros positivos y los negativos con otros negativos reforzando en cada caso la cadena propia.

La configuración de la identidad femenina, desde la perspectiva de género, está sujeta, por su propia condición biológica, y vinculada inexorablemente a una función reproductora, lo que implica que la identidad de la mujer está constituida desde una triple dimensión: biológica, psicológica y social, englobada en un complejo ciclo vital. Este modo de configuración de la identidad femenina supone la implicación de una serie de dicotomías: mujer versus

1. SAU, V. Ser mujer: El fin de una imagen tradicional. Barcelona, Icaria, 1986.

Feminismo/s 13, junio 2009, pp. 119-132 
hombre, naturaleza versus cultura, privado versus público, reproducción versus producción, intuición versus razón, cuerpo versus intelecto.... etc.

El género, por lo tanto, es un fenómeno constitutivo de las relaciones sociales fundadas sobre las diferencias percibidas entre los sexos y, asimismo resulta un primer modo de dar significado a las relaciones de poder ${ }^{2}$.

Esta identificación de la mujer con el ámbito privado, con la reproducción, y esta desvalorización del sexo femenino han sido legitimadas y justificadas desde la antigüedad, desde el saber vulgar hasta el científico, pasando por el filosófico o religioso. Es frecuente considerar a la mujer como un ser deficitario, carente y defectuoso, asignarle el terreno del amor y la sexualidad e identificar el ser mujer con el ser madre ${ }^{3}$.

Partiendo del presupuesto de que el proceso de construcción de la identidad de las personas es una realidad dinámica que se desarrolla por medio de las experiencias intersubjetivas y a lo largo de todo el ciclo vital, consideramos que existen variables como la discapacidad que pueden tener gran incidencia en el proceso de construcción (reconstrucción) de la identidad de las mujeres. No obstante, las formas y el nivel de tales efectos tendrían que ser diferentes. Puesto que el propio cuerpo es percibido y vivido en razón de los parámetros y expectativas socioculturalmente establecidas, especialmente en el caso de las mujeres, como un componente importante en el sentido del self, que puede ser, a su vez, fuente de gratificaciones o de daños narcisistas.

El objetivo de este trabajo consiste en mostrar, a partir del análisis de discursos de mujeres con discapacidad, de qué manera el género y la discapacidad han ido configurando su identidad como pertenecientes a estos grupos sociales. Los resultados de lo que aquí presentamos forman parte de una investigación más amplia de Shum, Conde y Portillo ${ }^{4}$, en la que tratamos de aproximarnos a las condiciones de vida de las mujeres con discapacidad (educación, relaciones familiares, relaciones laborales trabajo, pareja, etc.) con el objetivo de conocer y tratar de comprender de qué manera es percibida por ellas mismas. Analizamos las situaciones descritas por 75 mujeres con discapacidad (58 mujeres con discapacidad física, 11 con discapacidad auditiva y

2. Lopez, G. A.; Crespo, M. A. «Indicadores parentales de la Educación en Identidad y Roles de Género: Contraste Generacional». Revista de Ciencias de la Educación, 193, enero-marzo (2003), pp. 45-61.

3. Castañada, A. M. Masculinidad y feminidad. Él, ella y yo. Estudio de género en adolescentes mujeres de nivel socioeconómico bajo, 2002, <http://www.psicocentro.com/cgi-bin/ articulo_s.asp?texto=art52001> consultado el 15-09-2004.

4. Shum, G.; COnde, Á.; PorTillo, P. Mujer, discapacidad y violencia. El rostro oculto de la desigualdad. Madrid, Ministerio de Trabajo y Asuntos Sociales, 2006. 
6 visual) a las que se les pasó un cuestionario, así como las de 11 a las que se les realizaron entrevistas en profundidad ( 9 mujeres con discapacidad física, 2 con discapacidad visual y 1 con discapacidad auditiva). A partir del análisis de sus discursos, realizamos una descripción de las representaciones del cuerpo que tienen este grupo de mujeres para las que la discapacidad supone un factor relevante en la construcción de su identidad y de qué manera algunas variables como el tipo de discapacidad (física o sensorial), el momento de aparición (nacimiento, niñez, adolescencia..), el grado de la minusvalía, el nivel de estudios y la edad, son variables que modulan diferencias en la autopercepción de la imagen corporal.

\section{Discapacidad, representación del cuerpo y roles de género}

El cuerpo es el primer material de que dispone el sujeto para elaborar su identidad. Gracias a los procesos socializadores, el grupo de pertenencia provee al individuo de ideas y valores que poco a poco va interiorizando, que le permiten diferenciar el suyo de otros cuerpos (en función del género, edad, grupo de pertenencia...) y hacen posible el desarrollo de ideas sobre sí mismo. En último término configuran los modos de pensar, sentir y actuar que van conformando una manera de ser con características propias. Este proceso dinámico se inicia en el momento del nacimiento, cambia por el propio crecimiento, el desarrollo de los rasgos sexuales, intelectuales y emocionales, continuando este cambio, a lo largo de la vida. Asimismo es producto de las interacciones de estos elementos con los contextos sociales: organización familiar, grupos de iguales, trabajo, etc. Al articularse subjetividad y cultura, en la identidad del sujeto están presentes desde los estereotipos culturales de género hasta las experiencias personales pasando por las vivencias relativas al contexto social (clase, edad, etnia...).

Como ya hemos expresado con anterioridad, una de las variables relevantes para la construcción de la identidad, es la variable género. Las diferencias se conforman a lo largo del proceso evolutivo y aunque la configuración de la identidad de género parte de la percepción de las diferencias corporales de niños y niñas dependen en su mayoría de las construcciones sociales y culturales.

\subsection{Discapacidad, estereotipos sociales y autopercepción}

Aunque hoy en día el colectivo de mujeres está transformando su identidad en una nueva, que surge de la conciencia de quién ha comenzado a ser y ejercer como actor social, aún restan aspectos importantes que modificar, como 
el relacionado con la percepción del aspecto físico. Desde el punto de vista social, las mujeres suelen ser juzgadas por la apariencia y, según se encuentren cercanas o alejadas del patrón estándar de belleza -cánones socialmente establecidos- se ven obligadas a enfrentarse a una presión originada a causa del cuerpo. Presión que causa un alto impacto en el desarrollo de la imagen y de la autoestima, produciendo prototipos inalcanzables para la mayoría de la población femenina, generando incluso una serie de trastornos y enfermedades, como por ejemplo la anorexia nerviosa, al identificar constantemente a través de los medios de comunicación la delgadez con el éxito. Este modelo social de belleza se encuentra tan interiorizado en muchas mujeres que, el no poder ajustarse al mismo, resulta limitante desde el punto de vista de la aceptación personal y representa un gran sufrimiento para las mismas, como podemos observar en el discurso de esta mujer con discapacidad auditiva (con un grado medio de discapacidad), que fue capaz de ir superando poco a poco las dificultades de comunicación derivadas de su déficit auditivo y en cambio encuentra muy difícil sobreponerse a las de su sobrepeso:

Es que desde pequeñita son cosas que he pasado negativas, entonces yo, verás yo nunca me he aceptado a mi misma, yo soy gorda, yo nunca me he aceptado así como soy, yo me comunico poco por eso, entonces me gustaría cambiar no sé, no sé cuando, a lo mejor algún día cambiaré. [...] odio a los hombres porque siempre me decían supergorda, eres gordísima, pero si tú no te vas a poder casar porque tu cama se te va a romper, porque estas muy gorda, porque no sé que, porque no sé cuanto, muchas cosas así, tú imagínate el complejo que a mi eso me puede crear, incluso yo he dicho, pues a partir de ahora ni esto, sólo con las mujeres y listo, ya poco a poco lo voy superando porque ya por fin la gente va mirando más tu cara no tu cuerpo, entonces lo importante es la comunicación, y eso lo estoy aprendiendo, entonces poco a poco me dicen que soy una lástima, que tengo la cara muy linda, pero eres muy gorda, entonces esos complejos se te van quitando, pero están ahí. [...]. Para mi la gordura, la gordura, antes cuando era pequeña yo era sorda y gorda, y me avergonzaba, pero ya, he ido a conferencias, he ido a jornadas, y me iba enterando que mi identidad, era una identidad de persona sorda, yo era sorda y como tal, y ahora ya el trauma que tengo es la gordura no la sordera.

De tal modo, ocurre que si una mujer es considerada bella, suele tener más éxito en su vida social y profesional, disfrutando de todas las posibles ventajas y del prestigio asociado a su género. Por el contrario, si una mujer carece de tales cualidades, estará destinada a sufrir y soportar cierto menosprecio, que afectará en muchos casos negativamente el desarrollo de su autoestima y autoconcepto. Ello supone una limitación importante en el desempeño adecuado y satisfactorio de las funciones y roles socialmente establecidos para 
su género, como se deriva del discurso de otra mujer con nivel de estudios medios y un alto grado de minusvalía asociado a su discapacidad física:

Pero vamos, que no te va a abrir las puertas el que sepas un $50 \%$ más que aquella, que como aquella sea guapa, tenga un físico agradable, la que va a entrar es ella y no tú.

Si al género añadimos la variable discapacidad, la percepción del cuerpo adquiere una especial relevancia para las mujeres, pues el hecho de que la imagen se aleje demasiado de la norma deseada resulta perjudicial para la autopercepción de la misma. Esto es, los sentimientos de adecuación y aceptación de la propia imagen repercuten, sin duda, en la conformación de la propia identidad. Algunas mujeres relatan cómo el sentirse diferentes les hace sufrir de un modo importante, así se manifiesta por ejemplo en el hecho que relata esta mujer con discapacidad física y con un grado bajo de minusvalía, que evita verse reflejada en los espejos:

O sea una cosa por ejemplo no he superado, cuando me veo en un espejo me pone mala, entonces es cuando la veo [la cojera] pero mientras voy andando yo ni lo veo, yo me veo normal.

Las mujeres con discapacidad tienen apariencias diferentes y, generalmente, alejadas de los estándares sociales, que suelen ser analizadas socialmente como déficit, y buena parte de ellas asumen como tales deficiencias, como le ocurre a esta mujer de 45 años con estudios medios y un alto grado de minusvalía física:

Sufro desde mi perspectiva. Es lógico que sufra ¿no? Porque ¿a quién no le gusta tener un cuerpo perfecto? Hay quien puede conseguirlo y quien no puede conseguirlo, y el que no puede conseguirlo... ¿qué pasa? ¿Se tiene que cruzar de brazos y morirse de pena en un rincón?

La autoimagen supone una valoración del propio cuerpo en relación a las normas sociales y la retroalimentación recibida de los demás. Eso nos expone una mujer de 40 años con una leve discapacidad física: «Imperfecta soy yo. Sí, pero en ese sentido, soy yo, físicamente, la imperfecta».

Cuando los mensajes negativos provienen de otras personas significativas (familiares, amigos, pareja), las descripciones físicas funcionan no sólo específicamente como tales, sino como generalizaciones que definen a la persona de forma global. De modo que resulta esperable que el proceso de construcción de la identidad del grupo de mujeres con discapacidad se vea especialmente afectado, al percibir el propio cuerpo según las expectativas sociales y los valores culturalmente relevantes. Así lo relata esta mujer con discapacidad física: «¿Complejos? A veces sí. Pero a veces el complejo, yo pienso que es porque te lo hace ver la gente». 
Estos mensajes negativos de personas relevantes resultan más nocivos sobre todo en la niñez y la adolescencia, época del desarrollo en que se es más sensible a todo lo que tiene relación con el cuerpo y la imagen. Las mujeres con discapacidad realizan elaboraciones sobre sí mismas a partir de las expectativas que las personas cercanas tienen sobre ellas, aunque en muchas ocasiones se muestren en comportamientos de sobreprotección hacía ellas. Así lo expresa una mujer con discapacidad física que si bien mantenía una excelente relación con su hermana durante la adolescencia, ésta le ocultó que tenía novio para no incomodarla por si ese conocimiento la hacía sentirse inferior:

Cuando ella [mi hermana] tuvo novio, la última en enterarme fui yo, porque decía que tenía miedo de que yo tuviera envidia, no envidia, pero no sé... A mí me sentó mal que ella pensara eso, ¿porque yo, por qué iba a tener envidia? Pero en el sentido de que yo de aquella nunca, pues nunca había tenido relaciones con chicos, tenía amigos pero nunca había tenido una relación, entonces ella lo sabía, y en ese sentido no me lo contaba porque pensaba que yo o no estaba preparada o que no la iba a entender.

Un elemento de referencia importante en estas etapas del desarrollo y de clara influencia en la autoimagen es el grado de aceptación/rechazó del grupo de iguales. En general, las mujeres con discapacidad relatan situaciones de discriminación entre compañeros y compañeras, que suelen hacer referencia a sus características físicas o a la necesidad de usar algún tipo de prótesis (muletas, silla de ruedas, gafas...). Así lo manifiesta esta mujer con estudios superiores y un alto grado de minusvalía derivado de su deficiencia visual:

Se metían conmigo, me dejaban apartada. Estabas con un grupo de niños y a todos le decían que jugara menos a mí. Llevaba unas gafas de esas gordísimas, además la edad en la que las niñas empiezan a tontear un poco con los niños, no era tontear tanto... sino lo que dolía es que te apartaran, que te discriminaran, y que al resto de las niñas las dejaran jugar y a ti te discriminaran.

Este hecho les lleva, en muchos casos, a autolimitarse a la hora de participar en actividades sociales, como explica esta mujer con una discapacidad visual severa:

[En la adolescencia] Sí, porque a nivel de chicos, tú tienes tu complejo de no ver, quizás ese complejo lo tenga todavía. Por el hecho de no ver, no me imagino con un chico vidente, o eso es mi caso, quizás soy yo la que me ponga una pantalla y me bloquee, y también por mi enfermedad, tampoco me planteo tener relaciones con un chico y tal es porque me van a rechazar precisamente por eso, porque estoy enferma. 
Así como al mantenimiento de una baja autoconsideración social y limitaciones en sus relaciones interpersonales, como relata esta mujer con discapacidad física:

Sí. Sí he tenido relación con chicos, sí. De todas formas nunca he tenido un novio duradero. [E: Y por qué] Supongo que porque, hombre, al principio, porque yo nunca creí que pudiera gustar a nadie, sinceramente.

Algunas mujeres describen el modo en que buscan estrategias de diverso tipo para tratar de disimular la discapacidad. En el primer caso, se trata de una pequeña minusvalía por lo que esta mujer trata de esconder su cojera utilizando una bicicleta para desplazarse. En el segundo caso, la minusvalía es mayor, por lo que no duda en someterse a cirugía para poder superarla:

Yo procuraba no salir, yo siempre estaba en mi casa y cuando salía alguna vez en bicicleta, porque a mi me gusta mucho la bicicleta y entonces mi padre me compró la bicicleta, y yo siempre iba en bicicleta porque me sentía segura en la bicicleta en el sentido de que voy viendo los paisajes y nadie sabe que soy coja.

A los 14 años me empeñé en operarme porque empezaba a darme cuenta de los complejos y mi madre me dijo que no tenía que volverme a operar porque ya podía moverme.

\subsection{Discapacidad, sexualidad y maternidad}

En las sociedades occidentales se considera la sexualidad como elemento importante de la personalidad adulta pero, para el imaginario social, las mujeres con discapacidad no tienen deseos sexuales, por lo que se les niega ese derecho infantilizándolas. Se piensa que las mujeres con discapacidad no son sujetos sexualmente deseables. Se las ve como seres asexuados, que no tienen necesidades erótico-afectivas, o que son sexualmente incompetentes ${ }^{5}$. Esta consideración lleva pareja, en muchas de ellas, la inhibición de su deseo de establecer relaciones afectivas y sexuales, y el no considerarse sexualmente atractivas, como explica esta mujer con discapacidad física severa y estudios superiores:

[...], a ti te puede atraer un chico físicamente y sorprenderte de que tú le atraigas físicamente, y decir ¿qué verá este tío en mí?, con todas las tías guapas que hay por ahí, ¿qué verá ese tío en mí?

A veces esta inhibición se debe al miedo a ser rechazadas, como se evidencia del discurso de esta mujer con una discapacidad física de grado medio: «Quizás cuando conocí a mi marido, un poco sí, por ser minusválida quizás yo

5. Bosch, E. y Ferrer, E. A. La voz de las invisibles. Madrid, Cátedra, 2002.

Feminismo/s 13, junio 2009, pp. 119-132 
pensaba que no se iba a acercar a mí o que me iba a rechazar». Y de esta mujer de sólo 26 años pero con una discapacidad física severa: «Yo nunca pensé que podría tener una pareja, porque quién iba a querer cargar conmigo».

Por lo general, tanto los familiares como la sociedad en su conjunto, se muestran más comprensivos hacia que los varones con discapacidad tengan relaciones de pareja que a que las tengan las mujeres. Este recelo podría explicarse por diversas razones. Una de ellas coincidiría con el miedo al embarazo, basándose en el supuesto de que aumentarían las posibilidades de nacimientos de personas con deficiencias (aun cuando son escasos los factores hereditarios en la mayoría de las discapacidades).

Al tiempo, se presupone la imposibilidad de que las madres con discapacidades puedan llevar una vida independiente y responsabilizarse del cuidado de los hijos. En general no se las ve preparadas para llevar una vida en pareja, con hijos y una familia propia. Socialmente sus hijos son vistos como «menores asistentes» y los padres -más frecuentemente las madres- como «dependientes $»^{6}$. Las propias mujeres con discapacidad acaban considerando que sus hijos sufren o se compadecen de ellos, a causa de su déficit:

Yo creo que hacen falta ayudas, para que ese tipo de niños [hijos de mujeres con discapacidad] vayan creciendo en la normalidad. De hecho los hijos pueden llegar a pasarlo mal en el colegio si un compañero se ríe de él porque su madre vaya en sillas de ruedas por ejemplo.

Por su condición de discapacidad, se les considera como personas enfermas y necesitadas de cuidados. Así que de mujer cuidadora -rol tradicional de la mujer-pasa a ser vista socialmente como persona necesitada de cuidados, tanto más cuando se trata de mujeres con discapacidad física («Para ellos [mis padres]... que no iba a ser capaz de llevar una casa...») o con discapacidad sensorial:

Por eso las madres siempre protegen, por ese miedo de la mujer. Por ejemplo yo estoy casada y tengo una niña de un año, y yo veo que mi madre se agobia porque dice: mi hija no escucha y si a mi nieta le pasa algo no se va a enterar, puede que la niña se caiga y mi hija esté de espalda y no la haya sentido...

Sin embargo, la realidad demuestra que las mujeres con discapacidad suelen encargarse del cuidado de los hogares, hermanos e hijos, que, además, no suelen ser los propios ${ }^{7}$. En este sentido se manifiestan varias mujeres con

6. KeIth, L. y MorRis, J. «Blancos fáciles: los derechos de la discapacidad sobre el debate sobre los "menores cuidadores"». En J. Morris (eds). Encuentros con desconocidas. Feminismo y discapacidad. Madrid, Narcea, 1997, pp. 109-135.

7. Jimenez, A. y Huete, A. Discapacidad y trabajo en España. Estudio de los procesos de inclusión y exclusión social de las personas con discapacidad. Madrid, Ministerio de Asuntos Sociales, 1997. 
discapacidad física y sin apenas estudios que debían cuidar de sus hermanos y de la casa:

Ellos [mis padres] no me dejaban trabajar fuera de casa, pero dentro de casa no me trataban como una persona, sino como una esclava. Mis hermanos no participaban, y como yo era la mayor tenía que fregar, limpiar... yo me tenía que hacer cargo de toda la familia.

Mi madre no me ayudaba a hacer la rehabilitación, con el pretexto de que tenía que cuidar a mis hermanos.

Los repetidos argumentos sobre la falta de autonomía y la necesidad de cuidados producen como práctica habitual una fuerte presión disuasoria ante la maternidad, basadas en dos razones: por un lado que los embarazos suponen un alto riesgo y por otro, hay un gran déficit de ayudas sociales para atender a sus hijos e hijas. Pero detrás de todo esto, se encuentra una realidad más cruel y discriminatoria, como es el hecho de que a la hora de elegir a la pareja, socialmente se induce a los hombres a valorar previamente la apariencia física y no las cualidades personales que pueden tener las mujeres con o sin discapacidad. Así se desprende del discurso de dos mujeres con una discapacidad física leve que no eran aceptadas por las familias de sus maridos:

A su familia si, a su familia si, bueno, pues mira a su familia, yo que sé, hasta cierto punto lo ví normal, quieren lo mejor para sus hijos, y si al principio llegó a estar muchos meses sin hablar con sus padres, cuando se enteraron de que salía con una persona coja, pues llegó a estar 8 meses en su casa sin hablar con sus padres, lo que pasa es que yo no lo sabía, claro, él no me decía nada, con el tiempo, sí me lo dijo, y sus padres decían ¿por qué no salía con una persona sana?, que iba a estar enferma, lo de siempre.

Porque un día me cogió la madre y me dijo que tenía que entender que su hijo merecía algo mejor que yo.

Estas apreciaciones conllevan autovaloraciones negativas que limitan sus expectativas y ponen coto a sus aspiraciones relacionales y afectivas:

Pues mira... su familia... iyo qué sé! hasta cierto punto lo vi normal, quieren lo mejor para sus hijos. Yo cogí y corté, porque creí que tenía razón la madre, de que no le convenía a su hijo.

\subsection{Discapacidad, imagen y empleo}

Un aspecto de gran relevancia para estos colectivos de mujeres es el hecho de que su discapacidad les suponga un handicap para el desempeño laboral. En nuestra sociedad, el trabajo remunerado entraña una de las vías fundamentales de integración. Supone la fórmula para conseguir la independencia, la realización personal y el reconocimiento como miembros activos del grupo 
social. Pues bien, para un amplio número de mujeres las oportunidades de empleo se encuentran en el sector terciario IMSERSO ${ }^{8}$. Sector en el que el aspecto físico es, cada vez más, una cualidad necesaria y en el que es habitual que se exija «buena presencia» para la contratación. La mujer con discapacidad -física, sobre todo- generalmente es considerada como persona incompleta, que no cumple con los cánones de belleza establecidos socialmente para las mujeres y que no se ajusta a los estándares físicos existentes ${ }^{9}$. Esta visión se deriva de una clara discriminación que dificulta su integración laboral y que, en último término, incide también en su autoestima y autopercepción negativa ${ }^{10}$.

Esta discriminación comienza manifestándose en las dificultades que supone el acceso al mercado laboral, cuando se presentan a la entrevista de trabajo son sencillamente rechazadas para el puesto por el hecho de tener una discapacidad manifiesta ${ }^{11}$, como corroboran en sus exposiciones las siguientes mujeres de 28, 29, 33 y 50 años respectivamente, con un nivel de estudios medios y que presentan una ligera discapacidad física:

De entrada le dije que yo era minusválida y me dijo que no hacía falta que fuera a la entrevista.

Me he sentido discriminada en el sentido ese de minusválida de llegar a un trabajo y saber positivamente nada más ver la cara de la persona que me está entrevistando de que no me van a llamar porque soy minusválida.

Por ejemplo en Continente no te cogen el currículo, porque piensan que no eres una buena imagen para su empresa o porque no vas a rendir como otras personas.

Porque a mí me pasaba también allá, lo que miran es la presencia. Y a veces los estudios no tienen nada que ver.

La razón la proporciona esta mujer con una minusvalía moderada debida a una discapacidad física, de 22 años y con estudios medios: una situación de discriminación debido a la (mala) imagen.

8. IMSERSO. Discapacidad y trabajo en España. Estudio de los procesos de inclusión y exclusión social de las personas con discapacidad. Madrid, Ministerio de Asuntos Sociales, 1997.

9. JimÉnEZ, A. Los factores personales en el empleo de las personas con discapacidad, 2002 $<$ http://usuarios.discapnet.es/AJimenez/encuesta/FactoresPersonalesEmpleoPD.doc>, consultado el 25-01-2005.

10. Portillo, I., Shum, G., Conde, A. y Lobato, H. «Mujer, discapacidad y empleo.Tejiendo la discriminación». Comunicación presentada en el VI Congreso de Escuelas Universitarias de Trabajo Social. Zaragoza, 17-19 mayo de 2006.

11. Oliver, M. Politics and language. Understanding the disability discourse. London, 1994 <http://www.leeds.ac.uk/disability-tudies/archiveuk/Oliver/pol\%20and\%20lang\%20 94.pdf> consultado el 15-07-2004. 
Sí, porque yo creo que las que hay verdaderamente no les llaman mucho la atención a los empresarios. Y si te quieren a lo mejor es para un puesto en el que no te vea la gente, porque puedes dar mala imagen ¿no? Entonces yo creo que más que medidas es mentalización de la gente que no está mentalizada de que, bueno, que estamos aquí, que somos exactamente iguales a los demás, y eso todavía no lo tienen muy claro'.

La exclusión que sufren en estos ámbitos lleva a muchas mujeres a no aceptar su situación y a procurar no relacionarse con personas de su colectivo, evitando pertenecer a asociaciones o grupos de personas con discapacidad. Así lo manifiesta esta mujer con estudios medios y una discapacidad física severa:

Conscientemente lo rechazas, el juntarte con gente discapacitada, yo sí. Lo que pasa que si tú conoces a una persona con discapacidad tampoco la vas a rechazar porque la tenga ¿no? Esta chavala es muy buena gente, yo congenié con ella. Pero que tampoco lo busco.

En algunos casos, incluso hablan de sí mismas como si no formaran parte del colectivo de personas con discapacidad, tan grande es la presión que supone el aceptar el prejuicio social que conlleva la pertenencia a este grupo social:

Pues tal día tengo que ir con los minusválidos, no digo tenemos que ir, sin darme cuenta hablo de ellos como si yo no perteneciera, cuando en realidad pertenezco a ellos. De tal forma, pues no te gusta llevar una etiqueta ¿no?'.

Pero esta visión no responde a la generalidad de las percepciones manifestadas por este colectivo de mujeres. Algunas opinan que la discapacidad es un aspecto relevante de su vida y lo reclaman como parte de sí mismas, ya que consideran que les ayuda a conformar su identidad. Así se manifiestan dos mujeres con un alto grado de minusvalía debida a su discapacidad física:

Yo, cuando me miro al espejo, no veo una persona con discapacidad, veo una persona normal, incluso, yo es que ya no veo la silla, yo me veo a mí, simplemente no tengo ningún tipo de problema.

Yo también mujer, pero mujer discapacitada porque no puedo separar una cosa de la otra, pero no por nada sino porque yo soy así, igual que no puedo separar mi color de piel. Sí, discapacitada en silla de ruedas.

Aunque son las mujeres con discapacidad física las que suelen manifestar en sus discursos una valoración más negativa de su imagen corporal (frente a las que tienen discapacidad auditiva, por ejemplo), encontramos que algunas de las que presentan el grado de minusvalía más alto, no tienen de sí mismas esta autopercepción. Quizás la explicación se encuentre en que al estar más alejadas de los prototipos y normas estéticas socialmente relevantes no los tengan como referencia y los cánones de belleza no les supongan la misma presión para su propia aceptación que para aquellas mujeres con discapacidad que se 
encuentran más cercanas a los mismos ${ }^{12}$. Así, de este modo pretenden hacer visible su condición sin que por ello se las estigmatice. Sienten que el estereotipo social negativo las presenta sólo como una pérdida cuando para algunas personas la deficiencia también puede suponer ganancias que no existirían sin ella. En síntesis, reivindican la discapacidad porque condiciona la forma que tienen de relacionarse con el mundo, configurándose como un factor determinante en la construcción de su identidad, al igual que otros elementos de sus vidas como el género o la etnia ${ }^{13}$.

\section{A modo de conclusión}

A modo de conclusión, podemos señalar que la discapacidad puede ser considerada sin lugar a dudas una variable que contribuye a la construcción de la identidad y la personalidad de los individuos que presentan algún tipo de déficit. No obstante, el modo en que afecta a mujeres y hombres es diferente, ya que interactúa con el género y modula alguno de los factores que intervienen en la construcción de la identidad de las mujeres con discapacidad. Las causas se encuentran en la base de la representación mental y simbólica, fruto de los estereotipos y roles existentes, diferente para hombres y mujeres en nuestra sociedad.

Uno de los aspectos que condiciona la formación de una autopercepción negativa es el significado social de la imagen ${ }^{14}$. Al no responder a los prototipos o normas estéticas de la cultura dominante y a los patrones prefijados socialmente, las mujeres con discapacidad sufren las consecuencias de los estereotipos sociales que, como es natural, ellas mismas también acaban interiorizando. Además de sufrir discriminaciones laborales, afectivas y relacionales, se les niega incluso la posibilidad de responder a algunos de los patrones tradicionalmente ligados al género femenino de esposas, madres y cuidadoras debidos a los prejuicios sociales sobre las discapacidad, que las considera como personas enfermas y necesitadas de $\operatorname{cuidados}^{15}$. Y es que, co-

12. LONSDALE, S. Women and Disability. The experience of physical disability among woman. London, MacMillan Education LTD, 1990.

13. CROW, L. «Nuestra vida en su totalidad.: renovación del modelo social de discapacidad». En J. Morris (eds). Encuentros con desconocidas. Feminismo y discapacidad. Madrid, Narcea, 1996, pp. 229- 250.

14. Molano, A. «La imagen social de las mujeres con discapacidad». Ponencia presentada en II Jornadas de Mujeres y discapacidad intelectual FEAPS. Madrid, 2007). http://www. feapsmadrid.org/export/sites/feaps/recursos/docs/noticias/2007/Ponecia_AnaMolano. pdf, consultado el 24-02-2008.

15. Barton, L. Discapacidad y sociedad. Madrid, Morata/Fundación Paideia, 1998, p. 209. 
mo señala Shakespeare ${ }^{16}$, los estereotipos sexistas refuerzan los prejuicios sobre la discapacidad,

...en ambos casos [mujeres y hombres] la dependencia, la vulnerabilidad y la debilidad son las asociaciones en la cultura patriarcal. Por consiguiente, las mujeres discapacitadas se representan de una manera especialmente negativa y pasiva.

Las mujeres que presentan alguna deficiencia física, psíquica o sensorial llevan sus experiencias personales a su condición de género. La percepción negativa de su cuerpo tiene una especial relevancia para las mujeres con discapacidad física, sobre todo aquellas cuyo grado de minusvalía es menor. Las mujeres con sordera sufren en menor medida este tipo de discriminación, ya que se ajustan más a los estándares sociales relacionados con la imagen, aunque también suelen padecer la presión que supone la exigencia de la buena presencia física para la mujer.

En un gran número de ocasiones, la autopercepción de estas mujeres es un reflejo del prejuicio social y una manifestación de cómo son vistas por los demás. Generalmente el prejuicio nace del desconocimiento y, aunque no es seguro que desaparezca totalmente con el simple contacto, es posible que se produzca un cambio de actitudes con respecto a ellas cuando se les permite integrarse en el contexto educativo, laboral, social, etc. como ciudadanas de pleno derecho. Sin embargo hay cierto número de mujeres para las que la discapacidad supone un elemento más, que conforma su propia imagen. No la visualizan como algo negativo, sino como un factor que debe ser tenido en cuenta a la hora de desarrollar cualquier actividad y que han asumido como algo que forma parte de su propia vida.

\section{Referencias bibliográficas}

Barton, L. Discapacidad y sociedad. Madrid, Morata/Fundación Paideia, 1998.

Bosch, E. y Ferrer, E. A. La voz de las invisibles. Madrid, Cátedra, 2002.

CASTAÑADA, A. M. Masculinidad y feminidad. Él, ella y yo. Estudio de género en ado-

lescentes mujeres de nivel socioeconómico bajo, 2002, <http://www.psicocentro. com/cgi-bin/articulo_s.asp?texto=art52001>, consultado el 15-09-2004.

Crow, L. «Nuestra vida en su totalidad.: renovación del modelo social de discapacidad». En J. Morris (eds). Encuentros con desconocidas. Feminismo y discapacidad. Madrid, Narcea, 1996, pp. 229-250.

16. ShAKESPEARE, T. «Poder y prejuicio: los temas de género, sexualidad y discapacidad». En Barton, Discapacidad y sociedad. Op. cit., pp. 205-229. 
IMSERSO. Discapacidad y trabajo en España. Estudio de los procesos de inclusión y exclusión social de las personas con discapacidad, Madrid, Ministerio de Asuntos Sociales, 1997.

JiMÉNEZ, A. Los factores personales en el empleo de las personas con discapacidad, 2002, $<$ http://usuarios.discapnet.es/AJimenez/encuesta/FactoresPersonalesEmpleo PD.doc>, consultado el 25-01-2005.

JimÉnez, A. y Huete, A. La discapacidad en cifras. IMSERSO, Madrid, 2002, http:// usuarios.discapnet.es/AJimenez/Documentos/AJL/discapacidad-en-cifras. pdf $>$, consultado el 25-01-2005.

KEITH, L. y MorRIS, J. «Blancos fáciles: los derechos de la discapacidad sobre el debate sobre los "menores cuidadores"». En J. Morris (eds). Encuentros con desconocidas. Feminismo y discapacidad. Madrid, Nancea, 1997, pp. 109-135.

LONSDAlE, S. Women and Disability. The experience of physical disability among woman, London, MacMillan Education LTD, 1990.

LOPEZ, G. A.; CRESPO, M. A. «Indicadores parentales de la Educación en Identidad y Roles de Género: Contraste Generacional». Revista de Ciencias de la Educación, 193 (enero-marzo 2003), pp. 45-61.

Molano, A. «La imagen social de las mujeres con discapacidad». Ponencia presentada en II Jornadas de Mujeres y discapacidad intelectual FEAPS. Madrid, 2007. http://www.feapsmadrid.org/export/sites/feaps/recursos/docs/noticias/2007/ Ponecia_AnaMolano.pdf, consultado el 24-02-2008.

Oliver, M. Politics and language. Understanding the disability discourse. London, 1994, <http://www.leeds.ac.uk/disability-studies/archiveuk/Oliver/pol\%20and\%20 lang\%2094.pdf>, consultado el 15-07-2004.

Portillo, I., Shum, G., Conde, A. y Lobato, H. «Mujer, discapacidad y empleo. Tejiendo la discriminación». Comunicación presentada en el VI Congreso de Escuelas Universitarias de Trabajo Social. Zaragoza, mayo 2006, pp. 17-19.

SAU, V. Ser mujer: El fin de una imagen tradicional. Barcelona, Icaria, 1986.

SHAKESPEARE, T. «Poder y prejuicio: los temas de género, sexualidad y discapacidad». En Barton, Discapacidad y sociedad. Madrid, Morata/Fundación Paideia, 1998, pp. 205-229.

Shum, G., Conde, Á. y Portillo, P. Mujer, discapacidad y violencia. El rostro oculto de la desigualdad. Madrid, Ministerio de Trabajo y Asuntos Sociales, 2006.

Shum, G., CONDE, Á. e IGLESIAS, M. La mujer con discapacidad física y su situación socio-laboral. A Coruña, Editorial Paideia, 1998. 